\title{
Th17 cells favor inflammatory responses while inhibiting type I collagen deposition by dermal fibroblasts: differential effects in healthy and systemic sclerosis fibroblasts
}

Nicolò Costantino Brembilla ${ }^{1 \dagger}$, Elisa Montanari ${ }^{1 \dagger}$, Marie-Elise Truchetet ${ }^{1}$, Elena Raschi ${ }^{2}$, Pierluigi Meroni ${ }^{2,3}$ and Carlo Chizzolini ${ }^{*}$

\begin{abstract}
Introduction: T helper (Th)-17 cells are increased in systemic sclerosis (SSc). We therefore assessed whether Th17 cells could modulate the inflammatory and fibrotic responses in dermal fibroblasts from healthy donors (HD) and SSC individuals.

Methods: Fibroblasts were obtained from 14 SSC and 8 HD skin biopsies. Th17 clones were generated from healthy peripheral blood upon enrichment of CC chemokine receptor (CCR)-4/CCR6/CD161 expressing cells. Their cytokine production was assessed by flow cytometry and multiplex beads immunoassay. Fibroblast production of monocyte chemoattractant protein (MCP)-1, interleukin (IL)-8, matrix metalloproteinase (MMP)-1, tissue inhibitor of metalloproteinase (TIMP)-1, MMP-2 and type-I collagen was quantified by enzyme-linked immunosorbent assay (ELISA) and radioimmunoassay (RIA), and changes in their transcription levels assessed by real-time PCR. Intracellular signals were dissected by western blot and the use of pharmacological inhibitors. IL-17A, tumor necrosis factor (TNF) and interferon-gamma (IFN- $\gamma$ ) blocking reagents were used to assess the specificity of the observed effects.

Results: IL-17A increased MCP-1, IL-8 and MMP-1 production in a dose-dependent manner while having no effect on type I collagen in HD and SSc fibroblasts both at protein and mRNA levels. Nuclear factor-kappa B (NF-KB) and p38 were preferentially involved in the induction of MCP-1 and IL-8, while MMP-1 was most dependent on C-Jun $\mathrm{N}$-terminal kinase (JNK). Supernatants of activated Th17 clones largely enhanced MCP-1, IL-8 and MMP-1 while strongly inhibiting collagen production. Of note, the production of MCP-1 and IL-8 was higher, while collagen inhibition was lower in SSc compared to HD fibroblasts. The Th17 clone supernatant effects were mostly dependent on additive/synergistic activities between IL-17A, TNF and in part IFN- $\gamma$. Importantly, the inhibition of type I collagen production induced by the Th17 clone supernatants was completely abrogated by blockade of IL-17A, TNF and IFN- $\gamma$ mostly in SSc fibroblasts, revealing an intrinsic resistance to inhibitory signals in SSc.

Conclusions: Our findings demonstrate that in vitro Th17 cells elicit pro-inflammatory responses while restraining collagen production. Thus, the increased Th17 cell number observed in SSc may impact on the inflammatory component of the disease simultaneously potentially providing a protective role against fibrosis.
\end{abstract}

\footnotetext{
*Correspondence: carlo.chizzolini@unige.ch

${ }^{\dagger}$ Equal contributors

${ }^{1}$ Immunology and Allergy, University Hospital and School of Medicine,

Rue Gabrielle Perret-Gentil 4, 1211, Geneva 14, Switzerland

Full list of author information is available at the end of the article
} 


\section{Introduction}

Systemic sclerosis (SSc) is an autoimmune disorder of unknown origin characterized by fibro-proliferative microangiopathy and progressive fibrosis of the skin and internal organs $[1,2]$. Fibrosis results from an overproduction of extracellular matrix (ECM) components by fibroblasts, especially type I collagen, accompanied by impaired ECM degradation. In early SSc, dermal fibroblasts display an inappropriate phenotype essentially characterized by increased proliferative potential, increased synthetic capacity, resistance to inhibitory signals and decreased apoptosis [1,2]. In addition to collagens and matrix metalloproteinases (MMP), fibroblasts release several pro-inflammatory chemokines, such as monocytes chemoattractant protein (MCP)-1 and interleukin (IL)-8, which may indirectly influence ECM remodeling [3]. Of interest, MCP-1 and IL-8 are increased in the skin and serum of SSc patients $[4,5]$ and appear to be critical in mediating bleomycin-induced lung and dermal fibrosis [6,7].

The mechanisms leading to dysregulated activation of fibroblasts in SSc are only partially understood. T cells infiltrate SSc skin early and fibroblasts with high synthetic activity localize in close proximity to the inflammatory infiltrate (reviewed in [8]). T helper (Th) 2 polarized responses have been shown to be dominant in SSc skin and lung [9-13]. Consistently, IL-4 and IL-13 were shown to have direct pro-fibrotic activities on fibroblasts both in vitro and in vivo [14]. In addition, we and others have reported that SSc individuals have increased Th17 cell counts in their peripheral blood and skin [15-21].

Th17 cells are physiologically implicated in protection against extracellular bacteria and fungi [22] and are thought to have pathogenic roles in various autoimmune diseases [23-25]. Th17 cells mainly produce IL-17A, in conjunction with IL-17 F, IL-21 and IL-22, and are enriched in the subset of $\mathrm{T}$ cells expressing the chemokine receptors CCR4 and CCR6 in the absence of CCR10 [26,27]. They further express the lectin receptor CD161 [28]. IL-17A has been shown to participate in the development of skin and lung fibrosis induced by bleomycin in mice $[29,30]$. In agreement with a potential profibrotic role, IL-17 was shown to enhance fibroblast proliferation in humans [15], as well as their production of pro-inflammatory cytokines (MCP-1, IL-6 and IL-8) and matrix metalloproteinases (MMP-1 and MMP-3) [31,32], and ICAM-1 expression [15]. However, Kurasawa and colleagues could not show enhanced type I and type III procollagen mRNA expression in human fibroblasts cultured in the presence of IL-17 [15]. Moreover, Nakashima et al. recently provided evidence for an anti-fibrotic effect of IL-17A in human fibroblasts via upregulation of miR-129-5p and downregulation of connective tissue growth factor and $\alpha 1$ (I) collagen [33]. In agreement with these findings, we observed that IL-17 decreased alpha-smooth muscle expression induced by transforming growth factor $\beta$ (TGF- $\beta$ ) in human fibroblasts and that the number of IL-17A + cells in SSc skin correlated inversely with skin fibrosis [34]. Thus, the role of Th17 cells in SSc remains uncertain. The aim of the present study was to investigate whether Th17 cells could promote phenotypic changes in dermal fibroblasts and compare fibroblast responses in healthy and SSc individuals. Our data highlight the direct role of Th17 cells in collagen inhibition accompanied by the simultaneous enhanced production of mediators of inflammation. Furthermore, the data stress the intrinsic resistance of SSc fibroblasts to inhibitory signals delivered by Th17 cells.

\section{Methods}

\section{Study population}

Fourteen SSc individuals (twelve women and two men) presenting at the Rheumatology Unit of the Gaetano Pini Hospital in Milan (Italy) or at the Immunology and Allergy department of the Geneva University Hospital (Switzerland) were prospectively included in the study. All patients met the American Rheumatism Association diagnostic criteria for SSc and were classified according to LeRoy et al. [35]. None of the patients were under systemic immunosuppressive therapy apart from a low dose of glucocorticoids ( $<6 \mathrm{mg}$ per day) at the time of sampling. Eight individuals had limited and six diffuse SSc. A biopsy was performed in the affected skin of the SSc individuals. The control group consisted of eight age and sex matched patients who underwent corrective breast or abdominal surgery at the department of plastic surgery of Clinique de La Tour in Geneva (Switzerland). None of the healthy individuals had dermatological disorders and none were under immunosuppressive agents or glucocorticoids. This study was approved by the ethical committee of the institutions involved (Comité departemental de médicine interne et médicine communautère des Hôpitaux Universitaires de Genève, Geneva, Switzerland; and the Institutional Review Board of the Istituto G. Pini, Milan, Italy) and was conducted according to the Declaration of Helsinki. Written informed consent was obtained from each individual.

\section{Reagents}

Anti-CD3 (clone OKT3) monoclonal antibody (mAb) was from the American Tissue Culture Collection (Manassas, VA, USA); anti-CD4-APC-Cy7, anti-CD45RA-FITC, antiCCR6-PerCP-Cy5.5, anti-CCR4-PE-Cy7, anti-CXCR3-APC, anti-CD161-APC and anti-CD28 mAbs from BD Biosciences (San Jose, CA, USA); anti-IL-4-APC, anti-IFN- $\gamma$-PE-Cy7 and anti-IL-17A-FITC, LEAF irrelevant control mAbs from Biolegend (San Diego, CA, USA); and anti-IL-22-PE, antiCCR10-PE, recombinant human (rh) IL-23, TGF- $\beta$, tumor necrosis factor $\alpha$ (TNF), IL-17 and anti-human IL-17 Ab from R\&D Systems (Abingdon, UK). Cytofix/Cytoperm 
fixation/permeabilization solution kit was from Becton Dickinson (San Diego, CA, USA); Ficoll-Paque Plus from GE Healthcare (Uppsala, Sweden); RPMI 1640, (Dulbecco's) modified Eagle's medium ((D)MEM), phosphate buffered saline (PBS), glutamine, penicillin, streptomycin, trypsin and fetal calf serum (FCS) from Gibco (Paisley, UK); phorbol myristate acetate (PMA), $\beta$-mercaptoethanol, $\alpha$-ketoglutaric acid, $\beta$-amino propionitrile, L-ascorbic acid, brefeldin A and nuclear factor-kappaB (NF-kB) peptide inhibitor TPCK from Sigma (St. Louis, MO, USA); rhIL-2 from Biogen (Cambridge, MA, USA); Dynal CD4 Negative Isolation kit from Invitrogen (Oslo, Norway) and phytohemagglutinin (PHA) from EY Laboratories (San Mateo, CA, USA). Radioimmunoassay (RIA) for type I procollagen (PINP-1) was from Orion Diagnostica (Espoo, Finland); and ionomycin, MEK1/2 pharmacological inhibitor U-0126, p38 inhibitor SB203580, JNK inhibitor SP-600125 and PI3K inhibitor LY294002 from Calbiochem (San Diego, CA, USA). TNFa soluble receptor p75 was a kind gift of Dr J Sims, Amgen, Seattle, WA, USA.

\section{Fibroblast culture}

Fibroblast cell strains were generated after $0.1 \%$ type I collagenase digestion of skin biopsies at $37^{\circ} \mathrm{C}$ for two hours. Adherent cells were grown in (D)MEM containing $1 \%$ nonessential amino acids, $1 \% \mathrm{~L}$-glutamine, $1 \%$ sodium pyruvate, $50 \mathrm{U} / \mathrm{ml}$ penicillin, $50 \mu \mathrm{g} / \mathrm{ml}$ streptomycin and $10 \%$ FCS. All experiments were performed with fibroblasts at passage 3 to 8 . Fibroblasts were seeded at $2 \times 10^{4}$ cells/ well in triplicate in 96-well plates for collagen and cytokine assays and at $1 \times 10^{5}$ cells/well in $35-\mathrm{mm}$ tissue culture plates for $\mathrm{qPCR}$ and western blot. Cultures were serumstarved overnight and incubated with the indicated reagents in (D)MEM containing 1\% FCS, $25 \mu \mathrm{g} / \mathrm{ml} \mathrm{L}$-ascorbic acid, $3.4 \mu \mathrm{g} / \mathrm{ml} \alpha$-ketoglutaric acid and $50 \mu \mathrm{g} / \mathrm{ml} \beta$-amino propionitrile to favor collagen maturation as described [36]. IL-17A was added at $30 \mathrm{ng} / \mathrm{ml}$ (which fits in the ascending linear phase of the dose-response curve inducing significant effects, as shown in dose-response experiments in Figure 1A) unless otherwise stated, TGF- $\beta$ at $10 \mathrm{ng} / \mathrm{ml}$, TNF at 1 or $0.01 \mathrm{ng} / \mathrm{ml}$ anti-IL-17A, anti-IFN- $\gamma$ and irrelevant control $\mathrm{mAb}$ at $10 \mu \mathrm{g} / \mathrm{ml}$ (corresponding to a neutralizing antibody to recombinant IL-17A molar ratio of 50:1), anti-TNF (TNF-sRp759) at $10^{-8} \mathrm{M}$, Th17 supernatants at $1 / 50$ dilution. Supernatants were harvested at 48 hours and frozen until protein determination. Trypsinized cells were snap-frozen in liquid nitrogen and stored at $-80^{\circ} \mathrm{C}$ for total RNA extraction. Alternatively, cells were washed and immediately processed for western blot.

\section{T cell cloning}

CD4 + CD45RA- memory T cells (purity >99\%) were isolated from healthy peripheral blood mononuclear cells (PBMC) by negative selection coupling the Dynal
$\mathrm{CD} 4$ negative Isolation kit with anti-CD45RA mAb. The cells expressing CCR6 + CCR4 + CCR10- and CD161+ were stepwise positively sorted using FACSVantage (Becton Dickinson) to enrich for Th17 cells, resulting in a 7.8-fold enrichment of IL-17-producing CD4+ T cells compared to the parent population. The Th17-enriched cell strains were cloned by limiting dilution in the presence of $0.2 \times 10^{6}$ irradiated (3,500 Rad) allogeneic PBMC and $1 \mu \mathrm{g} / \mathrm{ml}$ PHA in complete RPMI supplemented with $20 \mathrm{U} / \mathrm{ml} \mathrm{IL-2}$ and $10 \mathrm{ng} / \mathrm{ml}$ of IL-23 as described [37]. The $\mathrm{T}$ cell clones obtained were screened for IL-17A, IL-22 and IFN- $\gamma$ production by intracellular fluorescence-activated cell sorting (FACS) analysis upon 4.5 hour PMA/Inomycin activation in the presence of brefeldin A with specific antibodies using FACSCanto (Becton Dickinson) flow cytometer and FlowJo software 7.5 (Tree Star, Ashland, OR, USA). Selected clones were activated or not by $1 \mu \mathrm{g} / \mathrm{ml}$ coated anti-CD3 and $1 \mu \mathrm{g} / \mathrm{ml}$ soluble CD28 antibodies and supernatants were harvested at 48 hours and frozen for further experiments.

\section{Chemokine, cytokine and collagen assays}

IL-22, MCP-1, MMP-1 and IL-8 were quantified in culture supernatants by ELISA (R\&D for IL-22, MCP-1, MMP1; Invitrogen for IL-8). Collagen production was assessed by RIA quantification of PINP (Orion Diagnostica) according to the manufacturer's instructions. IL-17A, IFN- $\gamma$, IL-4 and TNF were quantified by Luminex xMAP $^{\mathrm{TM}}$ Technology using multiplex beads immunoassay (Fluorokine MAP Multiplex Human Cytokine Panel, R\&D).

\section{Real-time quantitative PCR}

Total RNA was extracted from fibroblasts using an RNAesy micro kit (Qiagen, Hilden, Germany) and cDNA synthesized from $0.25 \mu \mathrm{g}$ of total RNA using random hexamers and Superscript III reverse transcriptase (Invitrogen, Carlsbad, CA, USA) according to the manufacturer's instructions. SYBR Green assays were performed on a SDS 7900 HT instrument (Applied Biosystems, Carlsbad, CA, USA). Each reaction was performed in triplicate. Raw cycle threshold $(\mathrm{Ct})$ values obtained with SDS 2.2.2 software (Applied Biosystems) were analyzed and the more stable housekeeping genes (GAPDH (glyceraldehyde3-phosphate dehydrogenase) and EEF1A1 (eukaryotic translation elongation factor 1 alpha 1)) selected for normalization. All oligonucleotides were obtained from Life Technologies (Carlsbad, CA, USA): CCL2 (F: AACCACAG TTCTACCCCTGGG; R:TAATGATTCTTGCAAAGACC CTCAA), IL8 (F:GCTCTCTTGGCAGCCTTCCT; R:TTA GCACTCCTTGGCAAAACTG), MMP1 (F: GGAGGAAA AGCAGCTCAAGAAC; R:TCCAGGGTGACACCAGTG ACT), COL1A1 (F: CCCTCCTGACGCACGG; R:GTGAT TGGTGGGATGTCTTCGT), COL1A2 (F:CTGTAAGAA AGGGCCCAGCC; R:GACCCCTTTCTCCACGTGG), 


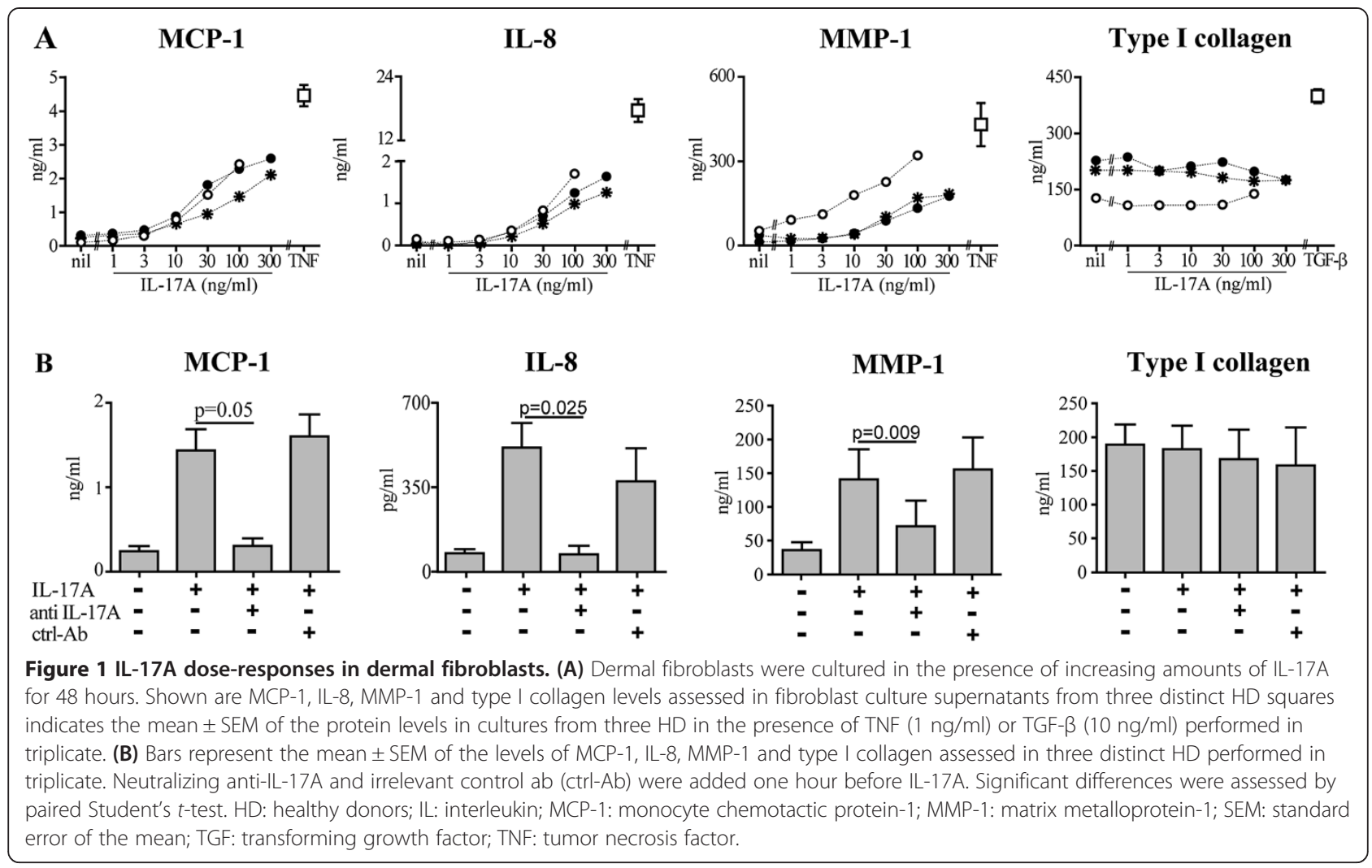

MMP2 (F: CTCACAGAACCCTTGGAGCC; R:CCAC CAGTGCCCTCTTGAGA), TIMP (F:CGTTATGAGA TCAAGATGACCAAGAT; R:CCCCTAAGGCTTGGA ACCC), IL-17RA (F:CCTGGAAGTGAAAAATACAG TGATGA; R:AGGCAGGCCATCGGTGT), IL-17RC (F:TGTGCAGTTTGGTCAGTCTGTG; R:GCCTCGAAG CAGTCATATACCAC), EEF1A1 (F: AGCAAAAATGACC CACCAATG; R:GGCCTGGATGGTTCAGGATA) and GAPDH (F: GCACAAGAGGAAGAGAGAGACC; R:AGG GGAGATTCAGTGTGGTG). Expression levels relative to the control condition were calculated using the $\Delta \Delta \mathrm{Ct}$ method.

\section{Western blot}

Fibroblasts were lysed for 10 minutes on ice in prechilled radioimmunoprecipitation assay (RIPA) buffer supplemented with $5 \mathrm{mM}$ ethylenediaminetetraacetic acid (EDTA), $50 \mathrm{mM}$ NaF, $1 \mathrm{mM}$ NasVO4, $100 \mathrm{mM}$ okadaic acid, 1X Complete Protease Inhibitor Cocktail (Roche, Basel, Switzerland) and $0.2 \mathrm{mM}$ phenylmethylsulfonyl fluoride (PMFS). Protein extracts were clarified by centrifugation and stored at $-20^{\circ} \mathrm{C}$ until use. For western blot, $30 \mu \mathrm{g}$ of total protein extract were separated in 10\% SDS-PAGE, under reducing conditions, and electroblotted onto nitrocellulose membranes (Amersham ${ }^{\mathrm{TM}}$ Hybond $^{\mathrm{TM}}$-ECL, GE Healthcare Zurich, Switzerland). Blots were incubated with antibodies against phospho-extracellular signal-regulated kinase (ERK)1/2 (Thr202/Tyr204), phospho-p38 (Thr180/ Tyr182), phospho-c-Jun (Ser73), phospho-Smad2 (Ser465/ 467), ІкB- $\alpha$, phospho-IкB- $\alpha($ Ser32), phospho-AKT (Ser473) (Cell Signaling, Danvers, MA, USA), phospho-c-Jun N-terminal kinases (JNK) (G-7) (Santa Cruz Biotechnology, Inc., Santa Cruz, CA, USA) and $\beta$-tubulin (Sigma). Horseradish peroxidase-conjugated antisera were used to reveal primary binding, followed by detection by an ECL system (GE Healthcare). Quantification analysis was performed with ImageJ software (http://rsbweb.nih.gov/ij) and values were normalized to $\beta$-tubulin.

\section{Statistical analysis}

Statistical analysis was performed with GraphPad Prism version 4.00 (Graphpad Software, La Jolla, CA, USA). Significant difference between samples was computed using Student's $t$-test for paired or unpaired samples according to the experimental design. The Wilcoxon signed-rank test was used to compare fold changes in protein or mRNA levels relative to the control condition. A $P$ value $<0.05$ was considered statistically significant.

\section{Results}

IL-17A enhances MCP-1, IL-8 and MMP-1 but not type I collagen production in HD and SSc dermal fibroblasts Several lines of evidence indicate that Th17 cells and their hallmark cytokine IL-17A are increased in SSc [15-21]. We 
therefore assessed whether IL-17A can affect the capacity of dermal fibroblasts from SSc and HD to produce inflammatory cytokines and ECM components known to be upregulated in SSc. Expanding previous observations [15,31,32], IL-17A enhanced the production of MCP-1, IL-8 and MMP-1 in a dose-dependent manner (Figure 1A). Neutralization of IL-17A completely abrogated the responses induced by IL-17A, thus confirming the specificity of our findings (Figure 1B). MCP-1, IL-8 and MMP-1 responses were similar in SSc and $\mathrm{HD}$ fibroblasts at both the protein and mRNA levels (Figures 2 and 3A). Of interest, IL-17A, even at high doses, did not affect type I collagen production, which production was enhanced in response to TGF- $\beta$, used as positive control (Figures $1 \mathrm{~A}$ and $3 \mathrm{~A}$ ). With respect to the cohort analyzed, no difference in MCP-1, MMP-1, IL-8 and type I collagen production was observed between limited systemic sclerosis (ISSc) and diffuse systemic sclerosis (dSSc) individuals (Figure 2).

Consistently, IL-17A did not modify COL1A1 and COL1A2 mRNA levels both in SSc and HD fibroblasts (Figure 3A). Finally, IL-17A did not affect the mRNA levels of TIMP-1, and slightly, but significantly, enhanced $M M P 2$ mRNA in SSc but not HD fibroblasts (Figure 3B).

Together, our findings demonstrate that IL-17A directly contributes to fibroblast inflammatory responses by enhancing MCP-1 and IL-8 production, and simultaneously impacts on ECM turnover by favoring MMP-1 rather than type I collagen production.

IL-17A effects on pro-inflammatory chemokines (MCP-1, IL-8) and MMP- 1 are mediated by distinct signaling pathways

IL-17A binds to and signals via a heterodimeric IL-17 receptor composed of the IL-17RA and IL-17RC subunits. When compared to normal fibrobalsts, only dSSc but not ISSc fibroblasts showed higher IL-17RA mRNA relative levels (Figure 4). The relative levels of IL-17RC mRNA were similar across the three study groups (Figure 4). IL-17A activated several intracellular signaling pathways including
c-Jun/JNK, ERK 1/2, p38 and protein kinase B (AKT) as demonstrated by time-dependant modifications in their phosphorylation levels (Figure 5A and B). In addition, IL-17A induced the phosphorylation of the NF- $\mathrm{kB}$ inhibitor protein IkB $\alpha$, while it did not trigger Smad2-phosphorylation, which was high in response to the positive control, TGF- $\beta$ (Figure 5A and $\mathrm{B}$ ). The production of MCP-1, IL-8 and MMP-1 was reduced in the presence of the specific MAP Kinase Kinase (MEK)1/2 (upstream of ERK1/2) inhibitor U0126 and PI3K (upstream of AKT) inhibitor LY294002, suggesting a wide involvement of these pathways in transducing IL-17A signals (Figure 5C, dark gray bars). Interestingly, the increased production of the pro-inflammatory chemokines MCP-1 and IL-8, but not that of MMP-1 was abrogated by the p38 inhibitor SB203580 and the NF- $\mathrm{kB}$ inhibitor TPCK (Figure 5C, black bars). In contrast, MMP-1, but not pro-inflammatory chemokine production was strongly reduced when JNK was inhibited by SP-600125 (Figure 5C, light gray bars). Thus, our data indicate that IL-17A exploits distinct signaling pathways to favor the production of proinflammatory chemokines (p38 and NF- $\mathrm{BB}$ dependent) and MMP-1 (JNK dependent).

Th17 clones enhance MCP-1, IL-8 and MMP-1 and decrease type I collagen production to different extents in HD and SSc fibroblasts

We then investigated whether the effects induced by Th17 cells on dermal fibroblasts were similar to that induced by IL-17A. To this aim we generated human Th17 cell clones. Since the frequency of Th17 cells in the PBMC is very low (below 1\%), we adopted a strategy to generate Th17 clones by a stepwise approach. In a prototypical experiment, we found that $8.9 \%$ of the CD4 + CD45RA- peripheral blood $\mathrm{T}$ cells were producing IL-17A (1.5\% were producing IL-17A alone and 7.4\% IL-17A in conjunction with IL-22 and IFN- $\gamma$ ). The frequency of IL-17A-producing $\mathrm{T}$ cells was enriched up to $38.0 \%$ upon positive sorting of CCR4 + CCR6+ cells and to a further $70.1 \%$ after positive sorting of CD161+ cells
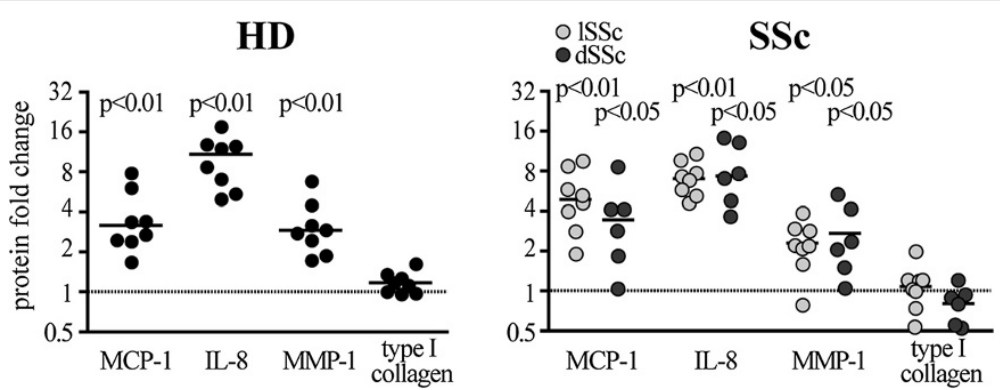

Figure 2 IL-17A enhances MCP-1, IL-8 and MMP-1 but not collagen production in HD and SSc fibroblasts. Dermal fibroblasts were cultured in the presence of $30 \mathrm{ng} / \mathrm{ml}$ of IL-17A. Protein levels are expressed as fold change relative to control condition (medium with no IL-17A, dotted line) assessed in 48-hour culture supernatants by ELISA (MCP-1, IL-8, MMP-1) and RIA (collagen). Each symbol represents a distinct individual and the horizontal lines depict the median. Significant differences relative to the control condition were assessed by the Wilcoxon signed-rank test. ELISA: enzyme-linked immunosorbent assay; IL: interleukin; MCP-1: monocyte chemotactic protein-1; MMP-1: matrix metalloprotein-1; RIA : radio-immune assay. 

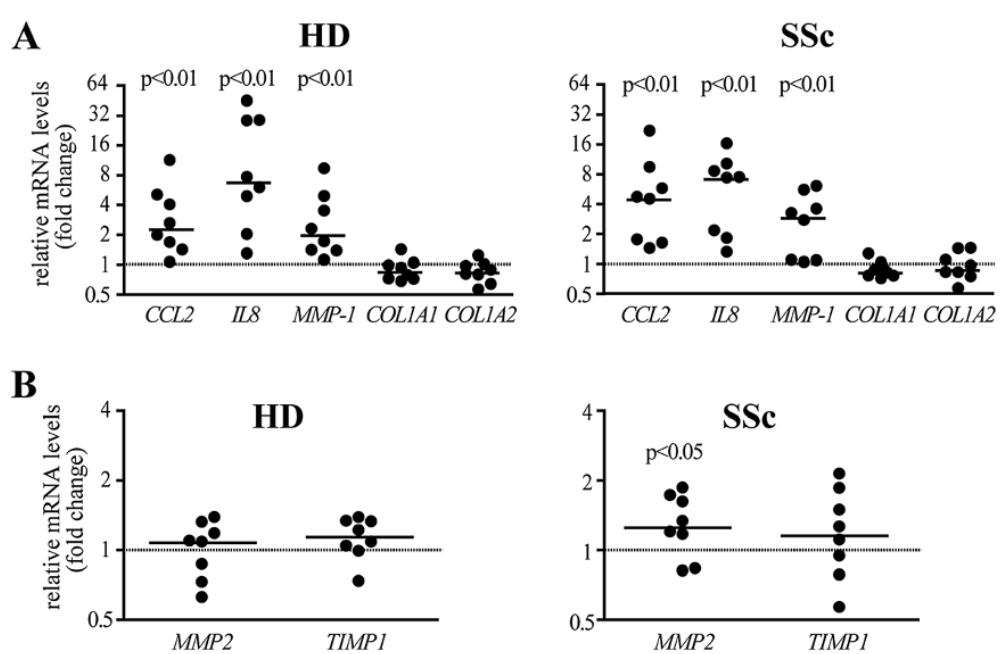

Figure 3 IL-17A enchances the mRNA levels of MCP-1, IL-8 and MMP-1 with no effects of COL1A1 and COL1A2 in HD and SSC fibroblasts.

(A-B) Steady-state mRNA levels were quantified by real-time PCR after 24 hours of culture. Expression levels were normalized against the geometric mean of two house-keeping genes (GADPH, EEF1A1). In all panels, the results are expressed as fold change relative to the control condition (medium with no IL-17A, dotted line) Each symbol represents a distinct individual and the horizontal lines depict the median. Significant differences relative to the control condition were assessed by the Wilcoxon signed-rank test. Fold increase induced by positive control TNF: $28 \pm 38$ (CCL2), $448 \pm 317$ (IL8), $18 \pm 22$ (MMP1), $1.5 \pm 0.5$ (MMP2), $1.6 \pm 0.7$ (TIMP1) and TGF- $\beta: 3.8 \pm 2.1$ (COL1A1), 1.8 \pm 0.6 (COL1A2). CCL: CC-chemokine ligand; COL: collagen; EEF1A1: eukaryotic elongation factor 1 alpha 1; GADPH: glyceraldehyde 3 phosphate dehydrogenase; HD: healthy donors; IL: interleukin; MCP-1: monocyte chemotactic protein-1; MMP-1: matrix metalloprotein-1; PCR: polymerase chain reaction; SSc: systemic sclerosis; TGF: transforming growth factor; TIMP: tissue inhibitor of matrix metalloproteinase; TNF: tumor necrosis factor.

(Figure 6A). This IL-17A + enriched T cell population was then cloned by limiting dilution. Several of the 20 screened clones (of 53 generated) produced high levels of IL-17A with variable levels of IL-22 and IFN- $\gamma$, thus being Th17 or Th17/Th1 cells [38] (Figure 6B). The supernatants of five distinct, representative clones were generated for further

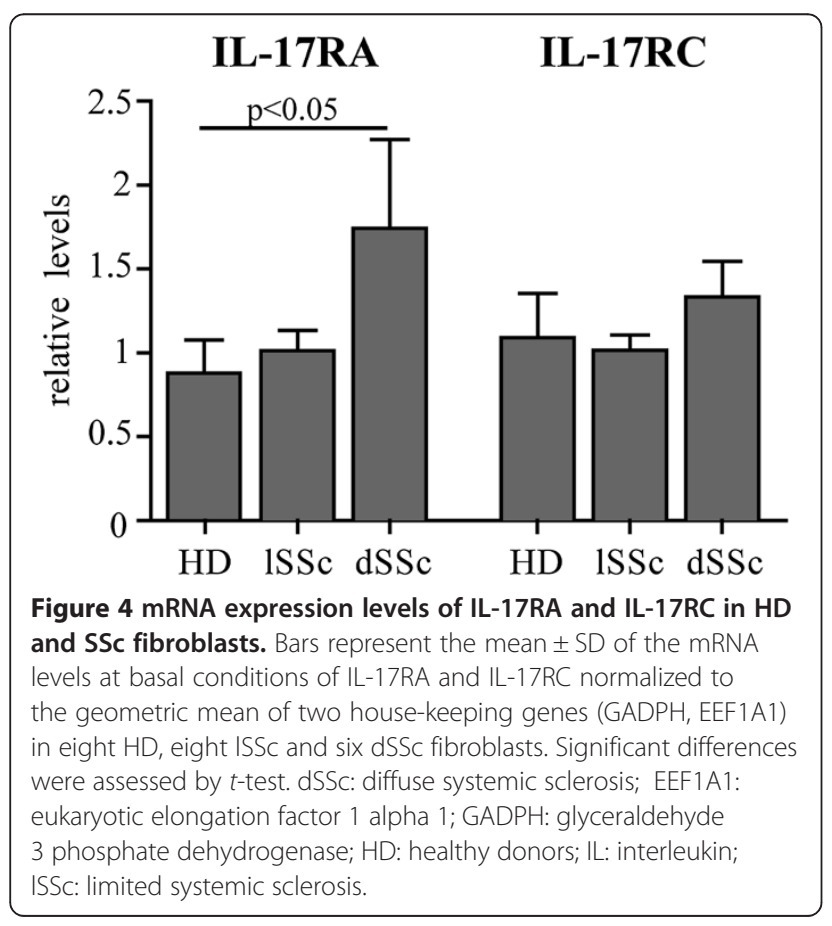

experiments. Of note, substantial amounts of TNF were produced by all clones (Figure 6C). All supernatants from activated, but not from resting, Th17 cell clones strongly induced MCP-1, IL-8 and MMP-1 and inhibited type I collagen production by both $\mathrm{HD}$ and SSc fibroblasts (Figure 7A and B). However, the production of MCP-1 and IL-8 was higher, while collagen inhibition was lower in SSc compared to HD fibroblasts (Figure 7B). When compared to recombinant IL-17A, Th17 cell clone supernatants induced higher levels of pro-inflammatory chemokines (MCP-1 and IL-8) and similar levels of MMP-1. Of note and different from IL-17A, Th17 clones strongly inhibited type I collagen production (Figures 2, 3 and 7). Thus, quantitative as well as qualitative differences were observed in fibroblast responses when stimulated by Th17 cell supernatants compared to recombinant IL-17A.

\section{Th17 cell supernatant effects are mainly mediated by} IL-17A, TNF and, in part, IFN- $\gamma$

As mentioned above and shown in Figure 6C, Th17 cell supernatants contained several cytokines in addition to IL17A. We, therefore, assessed to which extent the effects observed in fibroblasts were mediated by IL-17A. IL-17A blockade significantly decreased the production of IL-8, but not that of MCP-1 and MMP-1, induced by five different Th17 cell clones by both HD and SSc fibroblasts (Figure 8A, B and C). Similar effects were observed upon TNF blockade (Figure 8A, B and C). The simultaneous blockade of IL-17A and TNF resulted in a maximal 


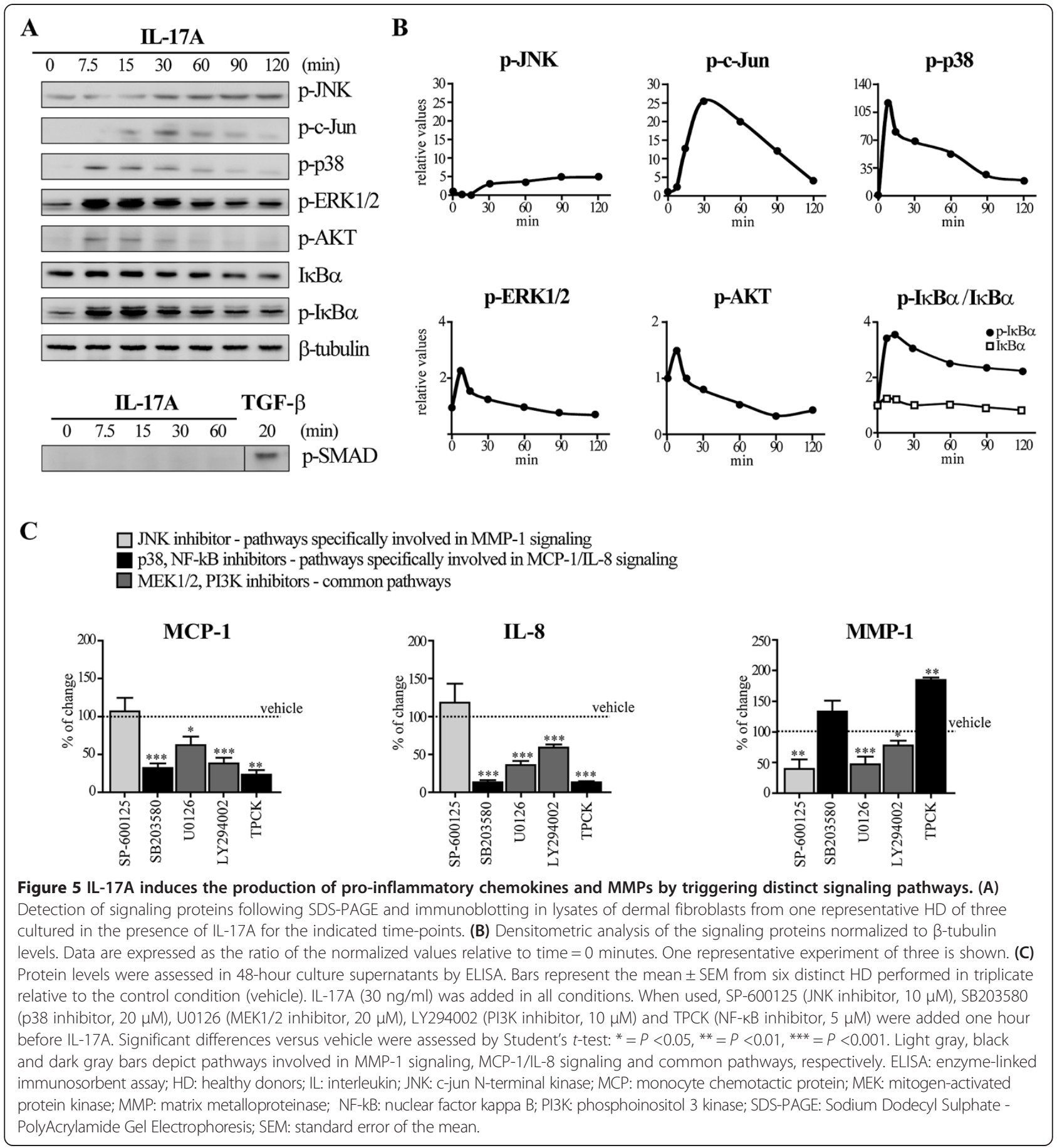

inhibition of IL-8 and MMP-1 (Figure 8A, B and C). In keeping with these observations, recombinant IL-17A synergized with recombinant TNF in enhancing IL-8 and MMP-1 production when added to HD fibroblasts (Figure 9). Of interest, IFN- $\gamma$ blockade in the same supernatants resulted in slightly decreased MCP-1 and strongly increased MMP-1 with no effect on IL-8 production (Figure 8A, B, C). Maximal inhibition of MCP-1 was observed when IL-17A, TNF and IFN- $\gamma$ were simultaneously blocked both in SSc and HD fibroblasts (Figure 8A, B, C). Interestingly, IL-17A or TNF blockade partially reverted the inhibition of type I collagen production induced by the Th17 cell clones in HD and only minimally in SSc fibroblasts (Figure 8D). Conversely, neutralization of IFN- $\gamma$ resulted in a reversion of collagen inhibition particularly in SSc and only minimally in HD fibroblasts, again stressing 


\section{A parental $\quad$ IL-17+ T cell enrichment}
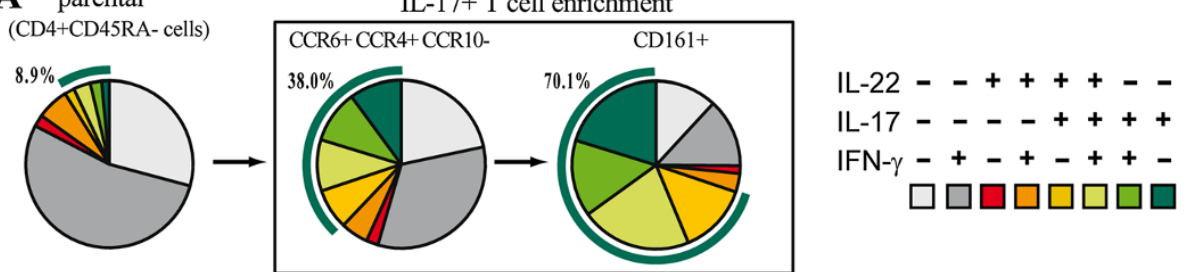

B

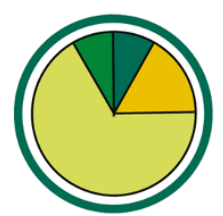

C

\begin{tabular}{|c|c|c|c|c|c|}
\hline & \multicolumn{5}{|c|}{$(\mathrm{pg} / \mathrm{ml})$} \\
\hline Clonename & IL-17A & IL-22 & IFN- $\gamma$ & IL-4 & TNF $\alpha$ \\
\hline 212B5 & 3,800 & 38,500 & 100 & 10 & 7,800 \\
\hline $212 \mathrm{D} 11$ & 28,200 & 65,300 & 3,400 & 60 & 9,300 \\
\hline $213 \mathrm{G} 3$ & 15,000 & 3,300 & 3,600 & 300 & 13,700 \\
\hline $206 \mathrm{H} 11$ & 13,800 & 11,300 & 4,900 & 10 & 12,400 \\
\hline 211E12 & 9,000 & 24,100 & 4,500 & 300 & 15,900 \\
\hline
\end{tabular}

Figure 6 Th17 cell clone generation and characterization. (A, B) Boolean gating analysis showing all combinations of IL-17A, IL-22 and IFN- $\gamma$ production by CD4 + CD45RA- memory T cells before and after stepwise enrichment based on CCR6 + CCR4 + CCR10- and CD161+ surface expression (A), and in the $20 \mathrm{~T}$ cell clones expanded after enrichment (B). Intracellular cytokine staining was performed after PMA and ionomycin stimulation. Color codes are shown in the right panel of A. The green circular segment indicates the total number of IL-17A-producing T cells after each step of enrichment. (C) T cell cytokine levels were measured in supernatants of five of the twenty activated Th17 cell clones by ELISA and bead immunoassay. CCR: CC-chemokine receptor; CD: cluster of differentiation; ELISA: enzyme immunosorbent assay; IFN: interferon; IL: interleukin; PMA: phorbol myristate acetate.
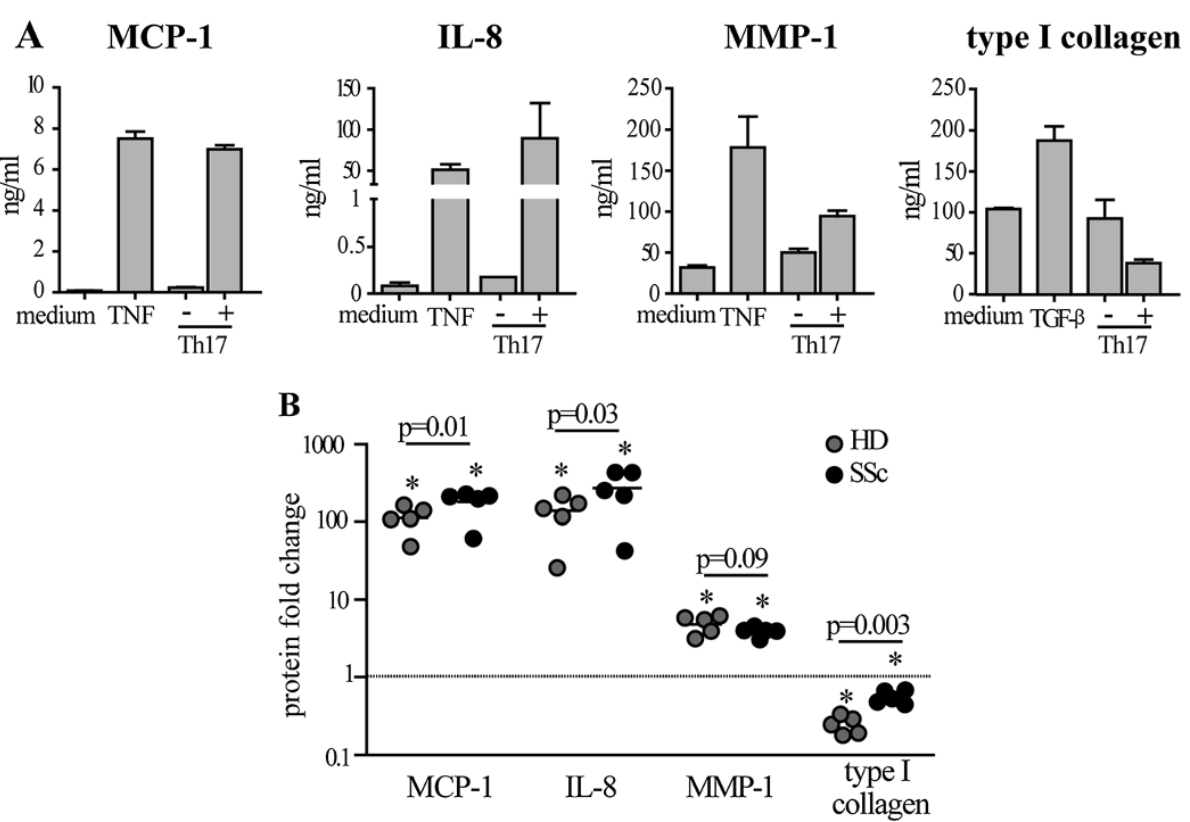

Figure 7 Th17 clones enhance MCP-1, IL-8 and MMP-1 and decrease type I collagen production by fibroblasts. (A) MCP-1, IL-8, MMP-1 and type I collagen production by HD fibroblasts cultured for 48 hours in the presence of supernatants of a prototypical Th17 clone supernatant before (-) or after (+) CD3/CD28 activation. TNF (1 ng/ml) and TGF- $\beta(10 \mathrm{ng} / \mathrm{ml})$ were used as positive controls. (B) Fold change relative to the control condition (dotted line) of MCP-1, IL-8, MMP-1 and type I collagen production by HD (gray) and SSc (black) fibroblasts cultured for 48 hours in the presence of supernatants from five distinct, activated Th17 clones. Each symbol represents an individual clone and the solid horizontal lines depict the median. Significant differences relative to the control condition were assessed by the Wilcoxon signed-rank test: ${ }^{*}=P<0.05$. Significant differences between HD and SSC are shown. CD: cluster of differentiation; HD: healthy donors; IL: interleukin; MCP-1: monocyte chemotactic protein-1; MMP-1: matrix metalloprotein-1; SSc: systemic sclerosis. 
A

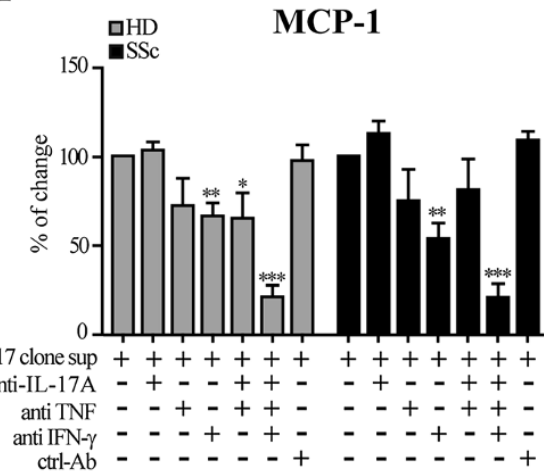

C

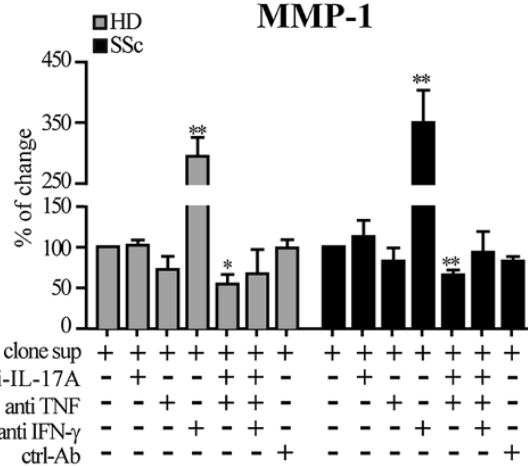

B

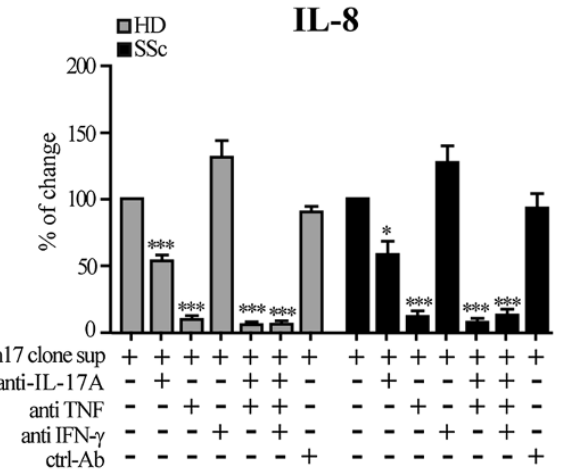

D

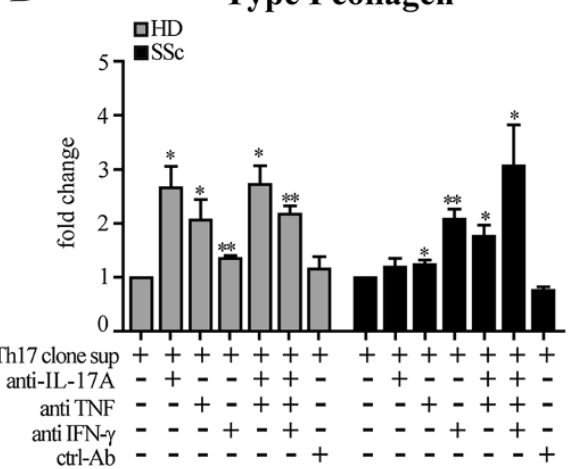

Figure 8 Th17 clone effects on fibroblasts are mediated in part by IL-17A, TNF and IFNp. MCP-1 (A), IL-8 (B), MMP-1(C) and type I collagen (D) production by HD (gray) and SSc (black) fibroblasts cultured for 48 hours in the presence of supernatants of five distinct, activated Th17 clones. Bars represent the mean \pm SEM of triplicate experiments. All data are expressed as the percentage of change relative to the condition in which the Th17 clone supernatants were added in the absence of blocking reagents (namely 'Th17 clone sup'). Anti-IL-17A (10 $\mu \mathrm{g} / \mathrm{ml})$, anti-IFN- $\gamma(10 \mu \mathrm{g} / \mathrm{ml})$, TNF-SRp75 $\left(10^{-8} \mathrm{M}\right)$ and $\mathrm{ctrl}$ Ab $(10 \mu \mathrm{g} / \mathrm{ml})$ were added one hour before the beginning of the culture. Shown are significant differences relative to the 'Th17 clone sup' condition ( ${ }^{*}=P<0.05 ;{ }^{*}=P<0.01$ ) assessed by paired $t$-test. ctrl: control; : healthy donors; IL: interleukin; IFN: interferon; MCP-1: monocyte chemotactic protein-1; MMP-1: matrix metalloprotein-1; PCR: polymerase chain reaction; SSc: systemic sclerosis; sup: supernatant; TNF: tumor necrosis factor; TNF-sRp75: tumor necrosis factor soluble receptor protein 75.

phenotypic differences intrinsic in SSc fibroblasts. Of major interest, the joint blockade of IL-17A and TNF or IL-17A, TNF and IFN- $\gamma$ resulted in the complete reversal of collagen inhibition induced by Th17 clones mostly in SSc fibroblasts (Figure 8D).

\section{Discussion}

In the present report, we show that Th17 cells elicit MCP-1, IL-8 and MMP-1 responses while simultaneously inhibiting type I collagen production in healthy and SSc dermal fibroblasts. Our data are consistent with a model in which Th17 cells participate in inflammatory events but not directly in enhanced collagen deposition. In this perspective, Th17 cells may be seen as cells with an important role in limiting the development of fibrosis. In line with our data, a recent work by Nakashima et al. indicated that IL-17A may have direct anti-fibrotic effects in human normal fibroblasts via upregulation of miR-129-5p and downregulation of connective tissue growth factor and type I collagen [15]. According to these authors, SSc fibroblasts may escape the negative control of IL-17A because of a reduced expression of the IL-17RA [15]. In our experimental settings, diffuse SSc fibroblasts expressed increased IL-17RA mRNA levels but, in partial agreement with Nakashima et al., we observed that collagen production by SSc fibroblasts was more resistant to inhibition by Th17 cells. Additional in vivo evidence consistent with this model was obtained when we studied the number of IL-17A + cells in the skin of SSc individuals and found that the total skin thickness score was higher when IL-17A + dermal cells were less numerous [34]. Of interest, Th17 cell numbers can be increased both in vitro and in vivo by iloprost, a $\mathrm{PGI}_{2}$ analog used in the clinical management of SSc digital ulcers, which may have beneficial effects on the disease course [39]. These data and our model are distinctly different from data and conclusions generated in rodents, in which IL-17 was shown to favor in vivo collagen deposition in models of bleomycin-induced skin as well as lung fibrosis $[29,30,40]$. Furthermore, in the thigh skin of mice 


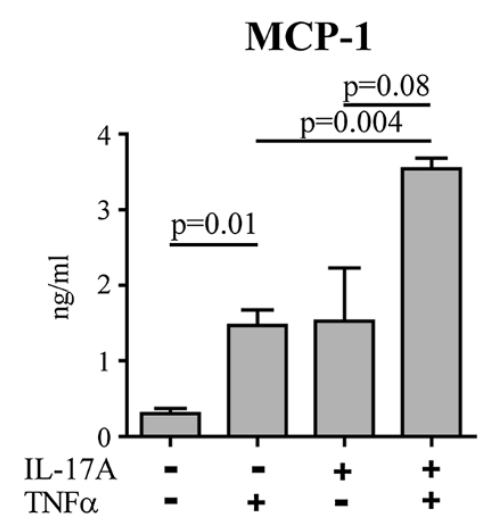

MMP-1

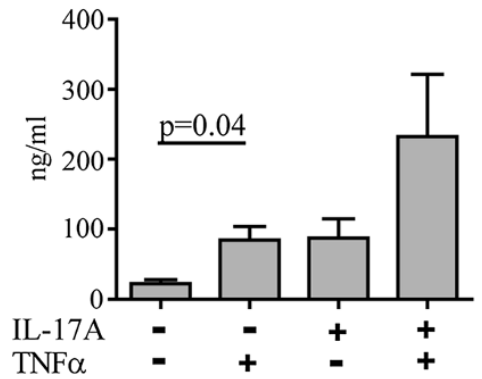

IL-8

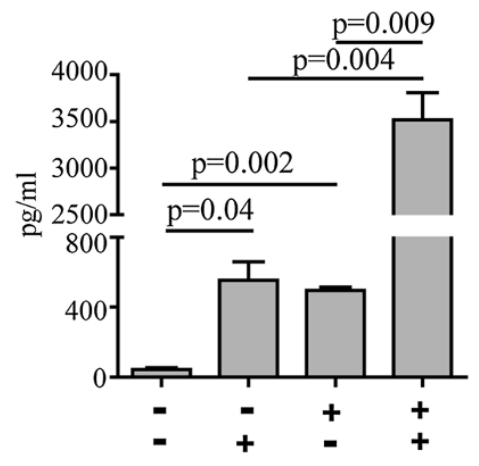

Type I collagen

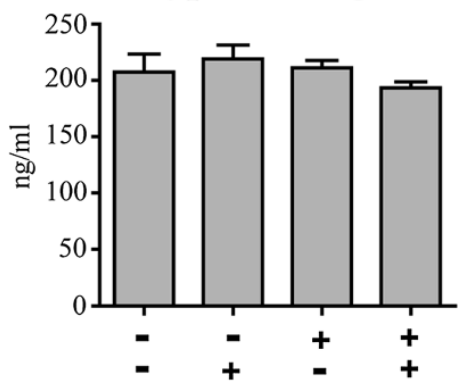

Figure 9 IL-17A synergizes with TNF to induce the production of MCP-1, IL-8 and MMP-1 by dermal fibroblasts. Bars represent the mean \pm SEM of the levels of MCP-1, IL-8, MMP-1 and type I collagen assessed in the supernatants of dermal fibroblasts from three HD cultured in triplicate for 48 hours in the presence or absence of IL-17A (30 ng/ml) and TNF (0.01 ng/ml). Statistically significant differences were assessed by paired t-test. HD: healthy donors; IL: interleukin; MCP-1: monocyte chemotactic protein-1; MMP-1: matrix metalloprotein-1; SEM: standard error of the mean; TGF: transforming growth factor; TNF: tumor necrosis factor.

lacking IL-17 the spontaneous fibrotic skin was reduced [30], and finally IL-17 neutralization decreased lung inflammation and fibrosis induced by silica [41]. The discrepancy between studies in humans and mice stresses speciesspecific differences in the responses induced by IL-17, as thoroughly discussed recently [8].

Our data clearly show that IL-17A directly promotes the production of pro-inflammatory mediators and MMP-1 by dermal fibroblasts from healthy and SSc individuals. Within the limits of the cohort investigated in this study, no differences were observed between limited and diffuse SSc individuals in this respect. These effects were largely amplified when supernatants from Th17 cell clones, producing high levels of IL-17, were assessed. Neutralizing experiments confirmed a critical role for IL-17A, at least in the case of IL-8, and revealed additive/synergic effects of IL-17 and TNF. Along this line of evidence, IL-17 was shown to enhance TNF-induced synthesis of IL-1, IL- 6 and IL- 8 by normal skin fibroblasts and osteoarthritis fibroblast-like synoviocytes [42]. MCP-1 and IL-8 are increased in skin and serum of SSc patients $[5,43]$ and reported to be critical in mediating lung and dermal fibrosis in bleomycin-treated mice [6,7]. However, whether these mediators have direct pro-fibrotic activities in humans is controversial. An increase in $\alpha 1$ (I) collagen mRNA was reported by northern blot hybridization in human dermal fibroblasts activated by MCP-1 [5], while later reports could not confirm these findings [44]. Similarly, MCP-1 was reported to increase the expression of MMP-1 and MMP-2, critical matrix degrading enzymes, but also the levels of their inhibitor TIMP-1 [45]. The role of these mediators in tissue fibrosis observed in mice may be related more to chemoattractant and angiogenetic properties than to a direct pro-fibrotic activity on fibroblasts or to its role in favoring priming of Th2 cells $[46,47]$.

We found that IL-17A enhanced MMP-1 production in dermal fibroblasts, as previously reported in human cardiac fibroblasts and fibroblast-like synoviocytes [48-51]. MMPs participate in tissue remodeling, directly acting on ECM but also modulating the activity of many important mediators regulating matrix deposition [52]. Despite its role as a degrading enzyme, MMP-1 levels have been paradoxically shown to be highly increased in human lung fibrosis [53], and variably reported to be increased, unchanged or decreased in SSc [54-57]. Thus, the exact role of MMP-1 in the development of fibrosis remains to be established.

We showed that IL-17A induced the production of proinflammatory chemokines preferentially via NF-кB and p38 
signaling pathways, while inducing MMP-1 via JNK. Consistent with our data, IL-17 was previously shown to promote IL-6/IL-8 production via NF-kB/Akt and NF- $\mathrm{KB} / \mathrm{MAPK}$ pathways in rheumatoid arthritis synovial fibroblasts and colonic myofibroblasts, respectively $[58,59]$ and in partial agreement with our findings, IL-17 induced MMP-1 production via activation of c-Fos/c-Jun AP1 and NF- $\mathrm{kB}$ in addition to MAPK signaling in cardiac fibroblasts [49].

Th17 cell clones were obtained after enrichment of cells expressing the chemokine receptor CCR6 and CCR4 in the absence of CCR10 [26,27] and the lectin receptor CD161 [28]. By applying this strategy, we obtained more than $70 \%$ of cells producing IL-17A. Compared to the expected numbers, the cloning procedure resulted in a slight enrichment of clones co-producing IL-17 and IFN- $\gamma$ (Th1/Th17 cells), suggesting a relationship between the Th1 and Th17 differentiation programs. In line with these results, a functional plasticity connecting Th1 and Th17 cells was recently reported both in vitro and in vivo $[28,38,60]$, although IL-17+/IFN- $\gamma+$ cells were shown to have a transcription profile closer to Th17 than to Th1 cells [38].

Of note, SSc fibroblasts were more prone to produce pro-inflammatory mediators (MCP-1, IL-8) and less sensitive to collagen inhibition when cultured in the presence of Th17 cell clone supernatants than their healthy counterpart. This suggests that SSc fibroblasts may escape or limit the anti-fibrotic effects induced by Th17 cells, and further stresses the existence of intrinsic differences between normal and SSc fibroblasts. In this context, it is worth noting that the inhibition of type I collagen production induced by the Th17 clone supernatants was partially reversed by blockade of IL-17 or TNF mainly in HD but not SSc fibroblasts while IFN- $\gamma$ neutralization had opposite effects. Again, the joint blockade of IL-17, TNF and IFN- $\gamma$ resulted in maximal effects, specifically in SSc but not HD fibroblasts. In agreement with previous evidence $[36,61]$, the present data strongly suggest that, compared to normal fibroblasts, SSc fibroblasts are more resistant to inhibitory mediators present in the Th17 cell clone supernatants.

In conclusion, our data are consistent with a model in which Th17 cells may participate in enhancing inflammation while simultaneously limiting fibrosis. It is worth noting that the contribution of Th17 cells to inflammatory conditions remains in many instances a matter of debate. As an example, the role of IL-17 in the initiation, progression and stabilization of atherosclerosis is currently controversially interpreted with evidence in favor of its proatherogenic potential and evidence in favor of its atheroprotective role [62]. Our findings stress for the first time the concomitant dual role of Th17 cells in the context of matrix deposition and may provide the functional basis for novel approaches to harness fibrotic diseases.

\section{Conclusions}

Th17 cells enhance in vitro fibroblast inflammatory responses while simultaneously inhibiting collagen production with a mechanism partially dependent on IL-17, TNF and IFN- $\gamma$. SSc fibroblasts are, however, intrinsically resistant to collagen inhibition induced by Th17 cells. Thus, the increased Th17 cell counts observed in SSc might be considered a manifestation of autoimmunity not mechanistically linked to fibrosis.

\begin{abstract}
Abbreviations
CCR: CC chemokine receptor; Ct: Cycle threshold; dSSc: Diffuse systemic sclerosis; ECM: Extracellular matrix; ELISA: Enzyme-linked immunosorbent assay; ERK: Extracellular signal-regulated kinase; FCS: Fetal calf serum; HD: Healthy donor; IFN-y: Interferon gamma; IL: Interleukin; JNK: c-Jun N-terminal kinases; ISSc: Limited systemic sclerosis; mAb: Monoclonal antibody; MCP: Monocytes chemoattractant protein; MEK: MAP kinase kinase; MMP: Matrix metalloproteinase; NF-kB: Nuclear factor-kappaB; PBMC: Peripheral blood mononuclear cell; PHA: Phytohemagglutin; RIA: Radioimmunoassay; SSc: Systemic sclerosis; TGF: Transforming growth factor; Th: T helper; TIMP: Tissue inhibitor of metalloproteinase; TNF: Tumor necrosis factor.
\end{abstract}

\section{Competing interests}

The authors declare that they have no competing interests.

\section{Authors' contributions}

NCB, EM and MET conceived and designed the experiments, and acquired, analyzed and interpreted the data. ER acquired the data and designed the experiments. CC conceived and designed research, and interpreted the data. PLM conceived and designed research. NCB and CC drafted the manuscript. All authors read and approved the final manuscript.

\section{Acknowledgements}

The work was supported in part by grant 310030_140791 from the Swiss National Science Foundation and a grant from the "Association des Sclérodermiques de France" to CC. EM was supported by a grant from the Manodori Foundation, Reggio Emilia, Italy. PLM and ER were supported by a grant from Ricerca Corrente IRCCS Istituto Auxologico Italiano, Italy.

\section{Author details}

${ }^{1}$ Immunology and Allergy, University Hospital and School of Medicine, Rue Gabrielle Perret-Gentil 4, 1211, Geneva 14, Switzerland. 'Experimental Laboratory of Immunological and Rheumatologic Researches, IRCSS Istituto Auxologico Italiano, Milan, Italy. ${ }^{3}$ Division of Rheumatology, Istituto G Pini, Department of Clinical Sciences and Community Health, University of Milan, Milan, Italy.

Received: 28 February 2013 Accepted: 25 September 2013 Published: 10 October 2013

\section{References}

1. Chizzolini C, Brembilla NC, Montanari E, Truchetet ME: Fibrosis and immune dysregulation in systemic sclerosis. Autoimmun Rev 2011, 10:276-281.

2. Varga J, Abraham D: Systemic sclerosis: a prototypic multisystem fibrotic disorder. J Clin Invest 2007, 117:557-567.

3. Hasegawa M, Sato S: The roles of chemokines in leukocyte recruitment and fibrosis in systemic sclerosis. Front Biosci 2008, 13:3637-3647.

4. Greenblatt MB, Sargent JL, Farina G, Tsang K, Lafyatis R, Glimcher LH, Whitfield ML, Aliprantis AO: Interspecies comparison of human and murine scleroderma reveals IL-13 and CCL2 as disease subset-specific targets. Am J Pathol 2012, 180:1080-1094

5. Yamamoto T, Eckes B, Hartmann K, Krieg T: Expression of monocyte chemoattractant protein-1 in the lesional skin of systemic sclerosis. J Dermatol Sci 2001, 26:133-139.

6. Ferreira AM, Takagawa S, Fresco R, Zhu X, Varga J, DiPietro LA: Diminished induction of skin fibrosis in mice with MCP-1 deficiency. J Invest Dermatol 2006, 126:1900-1908. 
7. Keane MP, Arenberg DA, Lynch JP 3rd, Whyte RI, lannettoni MD, Burdick MD, Wilke CA, Morris SB, Glass MC, DiGiovine B, Kunkel SL, Strieter RM: The CXC chemokines, IL-8 and IP-10, regulate angiogenic activity in idiopathic pulmonary fibrosis. J Immunol 1997, 159:1437-1443.

8. Brembilla NC, Chizzolini C: T cell abnormalities in systemic sclerosis with a focus on Th17 cells. Eur Cytokine Netw 2012, 23:128-139.

9. Atamas SP, Yurovsky W, Wise R, Wigley FM, Goter Robinson CJ, Henry P, Alms WJ, White B: Production of type 2 cytokines by CD8+ lung cells is associated with greater decline in pulmonary function in patients with systemic sclerosis. Arthritis Rheum 1999, 42:1168-1178.

10. Scaletti C, Vultaggio A, Bonifacio S, Emmi L, Torricelli F, Maggi E, Romagnani S, Piccinni MP: Th2-oriented profile of male offspring T cells present in women with systemic sclerosis and reactive with maternal major histocompatibility complex antigens. Arthritis Rheum 2002, 46:445-450.

11. Parel Y, Aurrand-Lions M, Scheja A, Dayer JM, Roosnek E, Chizzolini C: Presence of $\mathrm{CD} 4+\mathrm{CD} 8+$ double-positive $T$ cells with very high interleukin-4 production potential in lesional skin of patients with systemic sclerosis. Arthritis Rheum 2007, 56:3459-3467.

12. Fuschiotti P, Medsger TA Jr, Morel PA: Effector CD8+ T cells in systemic sclerosis patients produce abnormally high levels of interleukin-13 associated with increased skin fibrosis. Arthritis Rheum 2009, 60:1119-1128.

13. Medsger TA Jr, Ivanco DE, Kardava L, Morel PA, Lucas MR, Fuschiotti P: GATA-3 up-regulation in CD8+ T cells as a biomarker of immune dysfunction in systemic sclerosis, resulting in excessive interleukin-13 production. Arthritis Rheum 2011, 63:1738-1747.

14. Wynn TA: Cellular and molecular mechanisms of fibrosis. J Pathol 2008, 214:199-210.

15. Kurasawa K, Hirose K, Sano H, Endo H, Shinkai H, Nawata Y, Takabayashi K, Iwamoto I: Increased interleukin-17 production in patients with systemic sclerosis. Arthritis Rheum 2000, 43:2455-2463.

16. Murata M, Fujimoto M, Matsushita T, Hamaguchi $Y$, Hasegawa M, Takehara $K$, Komura K, Sato S: Clinical association of serum interleukin-17 levels in systemic sclerosis: is systemic sclerosis a Th17 disease? J Dermatol Sci 2008, 50:240-242.

17. Radstake TR, van Bon L, Broen J, Hussiani A, Hesselstrand R, Wuttge DM, Deng Y, Simms R, Lubberts E, Lafyatis R: The pronounced Th17 profile in systemic sclerosis (SSc) together with intracellular expression of TGFbeta and IFNgamma distinguishes SSc phenotypes. PLoS One 2009, 4:e5903.

18. Meloni F, Solari N, Cavagna L, Morosini M, Montecucco CM, Fietta AM: Frequency of Th1, Th2 and Th17 producing T lymphocytes in bronchoalveolar lavage of patients with systemic sclerosis. Clin Exp Rheumatol 2009, 27:765-772.

19. Truchetet ME, Brembilla NC, Montanari E, Allanore Y, Chizzolini C: Increased frequency of circulating Th22 in addition to Th17 and Th2 lymphocytes in systemic sclerosis: association with interstitial lung disease. Arthritis Res Ther 2011, 13:R166.

20. Fenoglio D, Battaglia F, Parodi A, Stringara S, Negrini S, Panico N, Rizzi M, Kalli F, Conteduca G, Ghio M, De Palma R, Indiveri F, Filaci G: Alteration of Th17 and Treg cell subpopulations co-exist in patients affected with systemic sclerosis. Clin Immunol 2011, 139:249-257.

21. Rodriguez-Reyna TS, Furuzawa-Carballeda J, Cabiedes J, Fajardo-Hermosillo LD, Martinez-Reyes C, Diaz-Zamudio M, Llorente L: Th17 peripheral cells are increased in diffuse cutaneous systemic sclerosis compared with limited illness: a cross-sectional study. Rheumatol Int 2011, 32:2653-2660.

22. Korn T, Bettelli E, Oukka M, Kuchroo VK: IL-17 and Th17 Cells. Annu ReV Immunol 2009, 27:485-517.

23. Langrish $\mathrm{CL}$, Chen Y, Blumenschein WM, Mattson J, Basham B, Sedgwick JD, McClanahan T, Kastelein RA, Cua DJ: IL-23 drives a pathogenic T cell population that induces autoimmune inflammation. J Exp Med 2005, 201:233-240

24. Murphy CA, Langrish CL, Chen Y, Blumenschein W, McClanahan T, Kastelein RA, Sedgwick JD, Cua DJ: Divergent pro- and antiinflammatory roles for IL-23 and IL-12 in joint autoimmune inflammation. J Exp Med 2003, 198:1951-1957.

25. Yen D, Cheung J, Scheerens H, Poulet F, McClanahan T, McKenzie B, Kleinschek MA, Owyang A, Mattson J, Blumenschein W, Murphy E, Sathe M, Cua DJ, Kastelein RA, Rennick D: IL-23 is essential for T cell-mediated colitis and promotes inflammation via IL-17 and IL-6. J Clin Invest 2006, 116:1310-1316.

26. Duhen T, Geiger R, Jarrossay D, Lanzavecchia A, Sallusto F: Production of interleukin 22 but not interleukin 17 by a subset of human skin-homing memory T cells. Nat Immunol 2009, 10:857-863.

27. Trifari S, Kaplan CD, Tran EH, Crellin NK, Spits H: Identification of a human helper $T$ cell population that has abundant production of interleukin 22 and is distinct from $\mathrm{T}(\mathrm{H})-17, \mathrm{~T}(\mathrm{H}) 1$ and $\mathrm{T}(\mathrm{H}) 2$ cells. Nat Immunol 2009, 10:864-871.
28. Cosmi L, De Palma R, Santarlasci V, Maggi L, Capone M, Frosali F, Rodolico G, Querci V, Abbate G, Angeli R, Berrino L, Fambrini M, Caproni M, Tonelli F, Lazzeri E, Parronchi P, Liotta F, Maggi E, Romagnani S, Annunziato F: Human interleukin 17-producing cells originate from a CD161 + CD4+ T cell precursor. J Exp Med 2008, 205:1903-1916

29. Wilson MS, Madala SK, Ramalingam TR, Gochuico BR, Rosas IO, Cheever AW, Wynn TA: Bleomycin and IL-1beta-mediated pulmonary fibrosis is IL-17A dependent. J Exp Med 2010, 207:535-552.

30. Okamoto Y, Hasegawa M, Matsushita T, Hamaguchi Y, Huu DL, Iwakura Y, Fujimoto M, Takehara K: Potential roles of interleukin 17A in the development of skin fibrosis. Arthritis Rheum 2012, 64:3726-3735.

31. Agarwal S, Misra R, Aggarwal A: Interleukin 17 levels are increased in juvenile idiopathic arthritis synovial fluid and induce synovial fibroblasts to produce proinflammatory cytokines and matrix metalloproteinases. J Rheumatol 2008, 35:515-519.

32. Fossiez F, Djossou O, Chomarat P, Flores-Romo L, Ait-Yahia S, Maat C, Pin JJ, Garrone P, Garcia E, Saeland S, Blanchard D, Gaillard C, Das Mahapatra B, Rouvier E, Golstein P, Banchereau J, Lebecque S: T cell interleukin-17 induces stromal cells to produce proinflammatory and hematopoietic cytokines. J Exp Med 1996, 183:2593-2603.

33. Nakashima T, Jinnin M, Yamane $K$, Honda N, Kajihara I, Makino T, Masuguchi S, Fukushima S, Okamoto Y, Hasegawa M, Fujimoto M, Ihn H: Impaired IL-17 signaling pathway contributes to the increased collagen expression in scleroderma fibroblasts. J Immuno/ 2012, 188:3573-3583.

34. Truchetet ME, Brembilla NC, Montanari E, Lonati P, Raschi E, Zeni S, Fontao L, Meroni PL, Chizzolini C: Interleukin-17A + cell counts are increased in systemic sclerosis skin and their number is inversely correlated with the extent of skin involvement. Arthritis Rheum 2013, 65:1347-1356.

35. LeRoy EC, Black C, Fleischmajer R, Jablonska S, Krieg T, Medsger TA Jr, Rowell N, Wollheim F: Scleroderma (systemic sclerosis): classification, subsets and pathogenesis. J Rheumatol 1988, 15:202-205.

36. Chizzolini C, Parel Y, De Luca C, Tyndall A, Akesson A, Scheja A, Dayer JM: Systemic sclerosis Th2 cells inhibit collagen production by dermal fibroblasts via membrane-associated tumor necrosis factor alpha. Arthritis Rheum 2003, 48:2593-2604.

37. Chizzolini C, Chicheportiche R, Alvarez M, de Rham C, Roux-Lombard P, Ferrari-Lacraz S, Dayer JM: Prostaglandin E2 synergistically with interleukin-23 favors human Th17 expansion. Blood 2008, 112:3696-3703.

38. Boniface K, Blumenschein WM, Brovont-Porth K, McGeachy MJ, Basham B, Desai B, Pierce R, McClanahan TK, Sadekova S, de Waal MR: Human Th17 cells comprise heterogeneous subsets including IFN-gamma-producing cells with distinct properties from the Th1 lineage. J Immunol 2010, 185:679-687.

39. Truchetet ME, Allanore Y, Montanari E, Chizzolini C, Brembilla NC: Prostaglandin 12 analogues enhance already exuberant Th17 cell responses in systemic sclerosis. Ann Rheum Dis 2012, 71:2044-2050.

40. Yoshizaki A, Yanaba K, Ogawa A, Asano Y, Kadono T, Sato S: Immunization with DNA topoisomerase I and Freund's complete adjuvant induces skin and lung fibrosis and autoimmunity via interleukin- 6 signaling. Arthritis Rheum 2011, 63:3575-3585

41. Mi S, Li Z, Yang HZ, Liu H, Wang JP, Ma YG, Wang XX, Liu HZ, Sun W, Hu $Z W$ : Blocking IL-17A promotes the resolution of pulmonary inflammation and fibrosis via TGF-beta1-dependent and -independent mechanisms. $\mathrm{J}$ Immunol 2011, 187:3003-3014.

42. Katz $Y$, Nadiv $O$, Beer $Y$ : Interleukin-17 enhances tumor necrosis factor alpha-induced synthesis of interleukins 1, 6, and 8 in skin and synovial fibroblasts: a possible role as a "fine-tuning cytokine" in inflammation processes. Arthritis Rheum 2001, 44:2176-2184.

43. Furuse S, Fujii H, Kaburagi Y, Fujimoto M, Hasegawa M, Takehara K, Sato S: Serum concentrations of the CXC chemokines interleukin 8 and growth-regulated oncogene-alpha are elevated in patients with systemic sclerosis. J Rheumatol 2003, 30:1524-1528.

44. Distler JH, Jungel A, Caretto D, Schulze-Horsel U, Kowal-Bielecka O, Gay RE, Michel BA, Muller-Ladner U, Kalden JR, Gay S, Distler O: Monocyte chemoattractant protein 1 released from glycosaminoglycans mediates its profibrotic effects in systemic sclerosis via the release of interleukin-4 from T cells. Arthritis Rheum 2006, 54:214-225.

45. Yamamoto T, Eckes B, Mauch C, Hartmann K, Krieg T: Monocyte chemoattractant protein-1 enhances gene expression and synthesis of matrix metalloproteinase- 1 in human fibroblasts by an autocrine IL-1 alpha loop. J Immunol 2000, 164:6174-6179. 
46. Gillitzer R, Goebeler M: Chemokines in cutaneous wound healing. I Leukoc Biol 2001, 69:513-521.

47. Lukacs NW, Chensue SW, Karpus WJ, Lincoln P, Keefer C, Strieter RM, Kunkel SL: C-C chemokines differentially alter interleukin-4 production from lymphocytes. Am J Pathol 1997, 150:1861-1868.

48. Chabaud M, Garnero P, Dayer JM, Guerne PA, Fossiez F, Miossec P: Contribution of interleukin 17 to synovium matrix destruction in rheumatoid arthritis. Cytokine 2000, 12:1092-1099.

49. Cortez DM, Feldman MD, Mummidi S, Valente AJ, Steffensen B, Vincenti M, Barnes JL, Chandrasekar B: IL-17 stimulates MMP-1 expression in primary human cardiac fibroblasts via p38 MAPK- and ERK1/2-dependent C/EBP-beta, NF-kappaB, and AP-1 activation. Am J Physiol Heart Circ Physiol 2007, 293:H3356-H3365.

50. Moran EM, Mullan R, McCormick J, Connolly M, Sullivan O, Fitzgerald O, Bresnihan B, Veale DJ, Fearon U: Human rheumatoid arthritis tissue production of IL-17A drives matrix and cartilage degradation: synergy with tumour necrosis factor-alpha, Oncostatin $\mathrm{M}$ and response to biologic therapies. Arthritis Res Ther 2009, 11:R113.

51. van Hamburg JP, Asmawidjaja PS, Davelaar N, Mus AM, Colin EM, Hazes JM, Dolhain RJ, Lubberts E: Th17 cells, but not Th1 cells, from patients with early rheumatoid arthritis are potent inducers of matrix metalloproteinases and proinflammatory cytokines upon synovial fibroblast interaction, including autocrine interleukin-17A production. Arthritis Rheum 2011, 63:73-83.

52. Page-McCaw A, Ewald AJ, Werb Z: Matrix metalloproteinases and the regulation of tissue remodelling. Nat Rev Mol Cell Biol 2007, 8:221-233.

53. Zuo F, Kaminski N, Eugui E, Allard J, Yakhini Z, Ben-Dor A, Lollini L, Morris D, Kim Y, DeLustro B, Sheppard D, Pardo A, Selman M, Heller RA: Gene expression analysis reveals matrilysin as a key regulator of pulmonary fibrosis in mice and humans. Proc Natl Acad Sci U S A 2002, 99:6292-6297.

54. Kuroda K, Shinkai H: Gene expression of types I and III collagen, decorin, matrix metalloproteinases and tissue inhibitors of metalloproteinases in skin fibroblasts from patients with systemic sclerosis. Arch Dermatol Res 1997, 289:567-572.

55. Young-Min SA, Beeton C, Laughton R, Plumpton T, Bartram S, Murphy G, Black C, Cawston TE: Serum TIMP-1, TIMP-2, and MMP-1 in patients with systemic sclerosis, primary Raynaud's phenomenon, and in normal controls. Ann Rheum Dis 2001, 60:846-851.

56. Toubi E, Kessel A, Grushko G, Sabo E, Rozenbaum M, Rosner I: The association of serum matrix metalloproteinases and their tissue inhibitor levels with scleroderma disease severity. Clin Exp Rheumatol 2002, 20:221-224.

57. Frost J, Ramsay M, Mia R, Moosa L, Musenge E, Tikly M: Differential gene expression of MMP-1, TIMP-1 and HGF in clinically involved and uninvolved skin in South Africans with SSc. Rheumatology (Oxford) 2012, 51:1049-1052

58. Hata K, Andoh A, Shimada M, Fujino S, Bamba S, Araki Y, Okuno T, Fujiyama Y, Bamba T: IL-17 stimulates inflammatory responses via NF-kappaB and MAP kinase pathways in human colonic myofibroblasts. Am J Physiol Gastrointest Liver Physiol 2002, 282:G1035-G1044.

59. Hwang SY, Kim JY, Kim KW, Park MK, Moon Y, Kim WU, Kim HY: IL-17 induces production of IL- 6 and IL-8 in rheumatoid arthritis synovial fibroblasts via NF-kappaB- and PI3-kinase/Akt-dependent pathways. Arthritis Res Ther 2004, 6:R120-R128.

60. Lee YK, Turner H, Maynard CL, Oliver JR, Chen D, Elson CO, Weaver CT: Late developmental plasticity in the Thelper 17 lineage. Immunity 2009, 30:92-107.

61. Chizzolini C, Rezzonico R, Ribbens C, Burger D, Wollheim FA, Dayer JM: Inhibition of type I collagen production by dermal fibroblasts upon contact with activated T cells: different sensitivity to inhibition between systemic sclerosis and control fibroblasts. Arthritis Rheum 1998, 41:2039-2047.

62. Butcher M, Galkina E: Current views on the functions of interleukin-17Aproducing cells in atherosclerosis. Thromb Haemost 2011, 106:787-795.

\section{doi:10.1186/ar4334}

Cite this article as: Brembilla et al:: Th17 cells favor inflammatory responses while inhibiting type I collagen deposition by dermal fibroblasts: differential effects in healthy and systemic sclerosis fibroblasts. Arthritis Research \& Therapy 2013 15:R151.

\section{Submit your next manuscript to BioMed Central and take full advantage of:}

- Convenient online submission

- Thorough peer review

- No space constraints or color figure charges

- Immediate publication on acceptance

- Inclusion in PubMed, CAS, Scopus and Google Scholar

- Research which is freely available for redistribution 